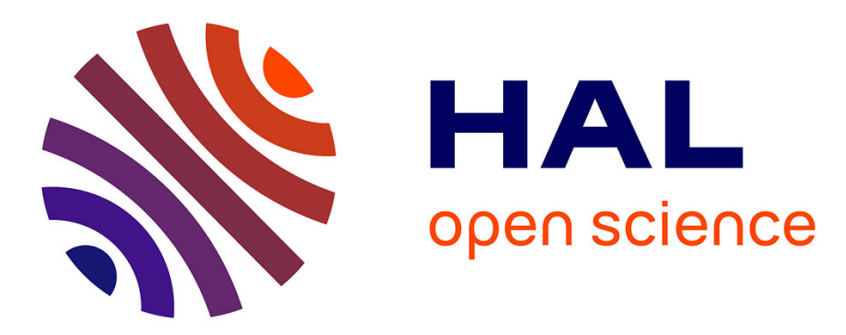

\title{
Electronic properties of neuroleptics: ionization energies of benzodiazepines
}

Salvatore Millefiori, Andrea Alparone

\section{To cite this version:}

Salvatore Millefiori, Andrea Alparone. Electronic properties of neuroleptics: ionization energies of benzodiazepines. Journal of Molecular Modeling, 2010, 17 (2), pp.281-287. 10.1007/s00894-010-0723-

7. hal-00590996

\section{HAL Id: hal-00590996 \\ https://hal.science/hal-00590996}

Submitted on 6 May 2011

HAL is a multi-disciplinary open access archive for the deposit and dissemination of scientific research documents, whether they are published or not. The documents may come from teaching and research institutions in France or abroad, or from public or private research centers.
L'archive ouverte pluridisciplinaire HAL, est destinée au dépôt et à la diffusion de documents scientifiques de niveau recherche, publiés ou non, émanant des établissements d'enseignement et de recherche français ou étrangers, des laboratoires publics ou privés. 


\section{Editorial Manager(tm) for Journal of Molecular Modeling Manuscript Draft}

Manuscript Number: JMM01191R1

Title: Electronic properties of neuroleptics: ionization energies of benzodiazepines

Article Type: Original paper

Keywords: Benzodiazepines; vertical ionization energies; vertical electron affinities; DFT calculations; electron propagator theory calculations.

Corresponding Author: Prof. Salvatore Millefiori,

Corresponding Author's Institution:

First Author: Salvatore Millefiori

Order of Authors: Salvatore Millefiori; Andrea Alparone

Abstract: Abstract. Vertical ionization energies (VIEs) of medazepam and nordazepam and of their molecular subunits have been calculated with the electron propagator method in the P3/CEP-31G* approximation. Vertical electron affinities (VEAs) have been obtained with a $\triangle$ SCF procedure at the DFT-B3LYP/6-31+G* level of theory. Excellent correlations have been achieved between IEcalc and IEexp allowing reliable assignment of the ionization processes. Our proposed assignment differs in many instances from the previously reported one in the literature. The electronic structure of the frontier Dyson orbitals shows that IE and EA values of the benzodiazepines can be modulated essentially by substitution at the benzene rings. Hardness values, evaluated as (IE-EA)/2, follow the trend of the experimental singlet transition energies. Medazepam is a less hard, i.e. less stable, compound than nordazepam.

Response to Reviewers: We agree with the comments of the referee. We submit the above manuscript revised accordingly. All comments of the referee have been taken into account. 


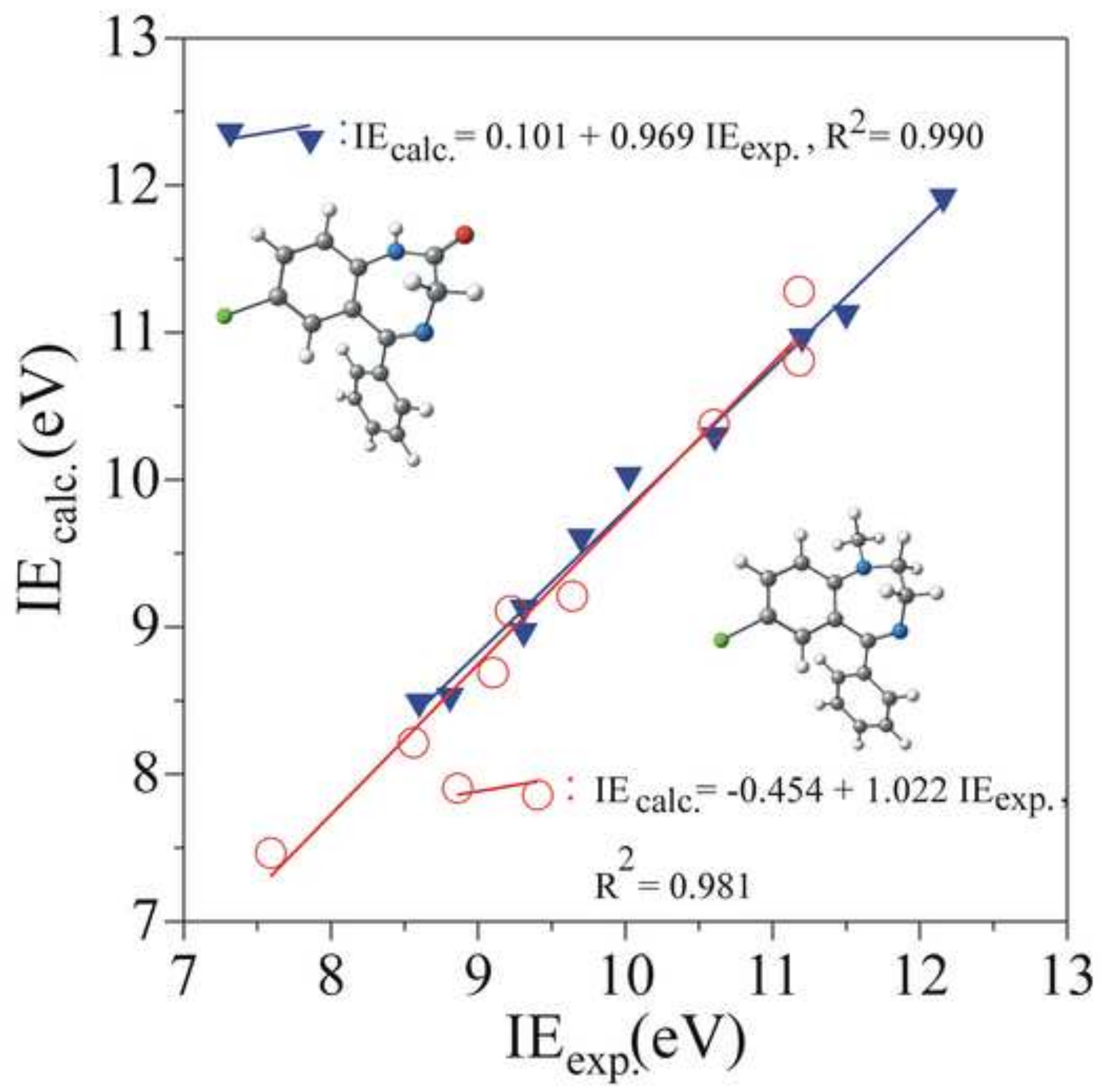




\title{
Electronic properties of neuroleptics: ionization energies of benzodiazepines
}

Received: 07.01.2010 / Accepted: 15.04.2010

Salvatore Millefiori ${ }^{\bowtie}$ and Andrea Alparone

Dipartimento di Scienze Chimiche,Università di Catania, Viale A. Doria 8, Catania 95125, Italy

${ }^{\circledR}$ Email address: smillefiori@unict.it

\begin{abstract}
Vertical ionization energies (VIEs) of medazepam and nordazepam and of their molecular subunits have been calculated with the electron propagator method in the P3/CEP-31G* approximation. Vertical electron affinities (VEAs) have been obtained with a $\triangle \mathrm{SCF}$ procedure at the DFT-B3LYP/6-31+G* level of theory. Excellent correlations have been achieved between $\mathrm{IE}_{\text {calc }}$ and $\mathrm{IE}_{\exp }$ allowing reliable assignment of the ionization processes. Our proposed assignment differs in many instances from the previously reported one in the literature. The electronic structure of the frontier Dyson orbitals shows that IE and EA values of the benzodiazepines can be modulated essentially by substitution at the benzene rings. Hardness values, evaluated as (IE-EA)/2, follow the trend of the experimental singlet transition energies. Medazepam is a less hard, i.e. less stable, compound than nordazepam.
\end{abstract}

Keywords Benzodiazepines - Vertical ionization energies - Vertical electron affinities • DFT calculations $\cdot$ Electron propagator theory calculations 


\section{Introduction}

Benzodiazepines are well known drugs of wide importance in medicinal chemistry, possessing a broad spectrum of pharmacological activity [1]. The heart of a benzodiazepine is constituted by a seven-membered partially saturated ring with nitrogen atoms at position 1 and 4, fused with a benzene ring. Substitution at the various positions of the two rings gives rise to a wide number of benzodiazepines derivatives. An accurate description of the electronic and molecular structure of representative compounds is of intrinsic value. In this respect, ultraviolet photoelectron spectroscopy (UV-PES), supported by reliable theoretical calculations, may provide precious information on the outer valence molecular orbital shapes and energies [2]. In this report we are dealing with the electronic structure of 7-chloro-5phenyl-1,3-dihydro-2H-1,4-benzodiazepin-2-one 6 (nordazepam) and molecular subunits 4 (ring D) and 5 (rings $\mathrm{B}$ and $\mathrm{D}$ ) and with 7-chloro-5-phenyl-2,3-dihydro-1-H-1,4benzodiazepin 3 (medazepam) and molecular subunits $\mathbf{1}$ (ring A) and $\mathbf{2}$ (rings B and A), Fig. 1. These compounds exhibit structural units present in several derivatives of the same family. The experimental UV-PES of compounds $\mathbf{3}, \mathbf{5}$ and $\mathbf{6}$ have been reported [3, 4]. The suggested assignments of the photoionization processes are, however, very different to each other. We aim to give an accurate description of the electronic structure of medazepam and nordazepam through the computation and the analysis of the outermost Dyson orbitals and the associated vertical ionization energies (VIEs) and vertical electron affinities (VEAs). To this end we employ the $a b$ initio electron propagator theory in the partial third order approximation (P3) [5]. P3 has been widely proved to give reliable interpretation of the ionization processes of a number of organic systems [6-8].

\section{Computational details}

P3 theory has been recently reviewed [9]. Briefly we recall that in the theory to every IE, there corresponds a Dyson orbital (DO) defined by

$$
\phi^{D y s o n}\left(x_{1}\right)=N^{-1 / 2} \int \Psi_{\text {cation }}^{*}\left(x_{2}, x_{3}, x_{4} \ldots . ., x_{N}\right) \times \Psi_{\text {molecule }}\left(x_{1}, x_{2}, x_{3} \ldots . ., x_{N}\right) d x_{2} d x_{3} d x_{4} \ldots . . d x_{N}
$$

where $\mathrm{N}$ is the number of electrons in the molecule and $\mathrm{x}_{\mathrm{i}}$ is the space-spin coordinate of electron i. To a DO is associated a so called pole strength, which indexes the validity of the perturbative treatment. Pole strength values between 0.85 and 1 indicate that the one-electron 
description of the ionization process is valid. In the P3 approximation DOs are proportional to Hartree-Fock orbitals. The P3 approximation includes orbital electron correlation and relaxation effects associated to the ionization. The active space included all valence occupied and all unoccupied molecular orbitals in P3 calculations of 1, 2, 4 and 5. In medazepam and nordazepam we considered all valence occupied molecular orbitals and $85 \%$ of the virtual molecular orbitals.

All calculations were performed with the Gaussian/03 program [10]. Molecular structures were fully optimized at the Density Functional Theory level (DFT) using the B3LYP functional $[11,12]$ and the $6-31 \mathrm{G}^{*}$ basis set. Due to the size of the investigated compounds, P3 calculations were carried out with the pseudo potential (PP) CEP-31G* basis set [13]. The $\mathrm{PP} / \mathrm{P} 3$ approach has been proved to be adequate in predicting VIEs [14]. Owing to the molecular size and the need of more extended basis set including diffuse functions, VEAs were computed by the widely used $\triangle \mathrm{SCF}$ procedure $[15,16]$ by comparing $a b$ initio B3LYP/6-31+G* total energies of the anion and neutral molecules on the geometry of the neutral compound.

\section{Results and discussion}

The molecular structures of compounds 1-6 are shown in Fig. 1. Starting geometries were taken, when available from X-ray data in the solid [17, 18]. To find minimum energy conformations we performed molecular dynamics (MD) simulation with AMBER force field for $1 \mathrm{~ns}$ at $600 \mathrm{~K}$ and a time step of $1 \mathrm{fs}$. The obtained conformations were optimized by AM1 calculations. The most stable structures were further fully optimized at B3LYP/6-31G* level. Theoretical geometries are in very good agreement with experimental data [17, 18]. Minimum energy conformations were confirmed by vibrational analysis. The seven-membered ring adopts a boat structure in $\mathbf{3}, \mathbf{4 , 5}$ and $\mathbf{6}$ and a twisted-boat structure in $\mathbf{1}$ and $\mathbf{2}$. Benzene ring $\mathrm{B}$ is planar. Benzene ring $\mathrm{C}$ can rotate around the single $\mathrm{C}-\mathrm{C}$ bond by producing in $\mathbf{3}$ two isoenergetic conformations with dihedral angles between the two benzene rings of $-157.3^{\circ}$ and $24.8^{\circ}$, respectively, separated by an energy barrier of $6.31 \mathrm{kcal} \mathrm{mol}^{1}$ with a maximum at $114.8^{\circ}$. The corresponding figures in 6 are: $-136.5^{\circ}, 27.7^{\circ}, 5.98 \mathrm{kcal} \mathrm{mol}^{1}, 123.4^{\circ}$ (Fig. S1 of the supplementary material). Cartesian coordinates of the minimum energy conformations are reported in Tables S1-S6 of the supplementary material. 
In the extensive work of Ortiz and co-workers P3 calculations were widely and successfully carried out with the $6-311 \mathrm{G}^{* *}$ basis set [19]. In the present work, owing to the size of the molecules we are dealing with, we used the smaller CEP-31G* basis set. The comparison of the CEP-31G* results with the 6-311G** ones and the experimental data for compound $\mathbf{5}$, as a test case, relative to the first five ionization energies, is given in Fig. 2. It can be seen that

$\mathrm{IE}_{\text {calc }}$ vs. $\mathrm{IE}_{\mathrm{exp}}$ correlation is similar for the two levels of theory and that experimental numerical data are well reproduced. In view of applying this methodology to larger related molecular systems we also tested the use of the even smaller CEP-31G basis set. The result, reported in Fig. 2 indicates a possible use also of this unpolarized double-zeta basis, although some energy shift is to be expected for orbitals with large nitrogen lone pair amplitude (third point in the correlation line of Fig. 2). Pole strength values of all the investigated compounds are between 0.87 and 1 , indicating that one-electron description of the final state is qualitatively valid.

Our theoretical electronic structure analysis starts from the isolated diazepine rings A and D followed by the more complex systems $\mathbf{2 , 5}$ and $\mathbf{3}, \mathbf{6}$.

\section{Vertical ionization energies}

\section{Compounds 1 and 4}

Dyson orbitals and energy levels of diazepine rings A and D are presented in Fig. 3. The first cationic final state of compound $\mathbf{1}$ is described by a rather high-energy $\pi_{\mathrm{C}=\mathrm{C}}$ orbital with contributions from $n \mathrm{~N}$ lone pairs. The methyl group gives a small contribution through hyperconjugative interaction. Next two IEs at 9.10 and $10.00 \mathrm{eV}$ pertain to $n \mathrm{~N}$ orbitals mainly localized on $\mathrm{N}_{4}$ atom. An in-phase $\pi \mathrm{C}=\mathrm{N}^{4}$ and $\mathrm{C}=\mathrm{C}-\mathrm{C}-\mathrm{N}^{1}$ combination characterizes the fourth ionization at $11.62 \mathrm{eV}$. Almost the same sequence of DOs characterizes the electronic structure of the diazepine ring $\mathrm{D}$ bearing the $\mathrm{C}=\mathrm{O}$ group but lacking the $\mathrm{CH}_{3}$ group. This substitution produces important changes in the orbital composition and IE values of the outermost final states, which all show contributions from the $n \mathrm{O}$ lone pairs and are stabilized owing to the strong electron withdrawing power of the $\mathrm{C}=\mathrm{O}$ group. Of particular significance is the $1.33 \mathrm{eV}$ stabilization of the lowest-energy DO. 


\section{Compounds 2 and 5}

Dyson orbital structures of compounds $\mathbf{2}$ and $\mathbf{5}$ are shown in Fig. 4 and the correlation diagram of the corresponding IEs in Fig. 5. The fusion of ring A and D with a benzene ring to give 2 and 5 introduces the $b_{1}$ - and $a_{2}$-like benzene orbitals, which give the major contribution to the first two energy levels in both compounds. They are followed by a cationic state essentially localized on an $\mathrm{N}^{4}$ lone pair, which in $\mathbf{5}$ has also some $n \mathrm{O}$ amplitude. The last two DOs in Fig. 4 have $\pi$ symmetry and are mainly localized on the benzene ring and on $N^{1}$ the former orbital and on the $\mathrm{C}=\mathrm{N}$ bond the latter one. Both compounds show the same succession of cationic states with IE values which are about $1 \mathrm{eV}$ higher in $\mathbf{5}$ than in 2 . Experimental IEs of 5 are known from photoelectron spectroscopy measurements [4] and are reported in Fig. 5 for comparison. On the basis of our calculations, the characterization of the electronic nature of the outermost cationic states differs in same instances from that proposed by Khvostenko et al. [4]. The most remarkable discrepancy lies in the assignment of the structured band at 9.4-9.6 eV which we assign to the ionization from the $\pi_{\mathrm{B}}\left(a_{2}\right)$ level at 9.17 $\mathrm{eV}$, while Khvostenko et al. associate this band to two ionizations of $\pi_{\mathrm{A}}\left(a_{2}\right)$ and $n \mathrm{~N}^{4}$ symmetry, respectively. Our assignment is supported by the observation that P3 calculations uniformly somewhat underestimate the experimental IE and by the fact that it produces, as previously seen, an excellent $\mathrm{IE}_{\text {calc }} v s$. $\mathrm{IE}_{\text {exp }}$ correlation (Fig. 2). A second main discrepancy refers to the assignment of the $\pi_{\mathrm{C}=\mathrm{N}}$ ionization, which Khvostenko et al. associate to the $\mathrm{IE}_{5}$ at $11.42 \mathrm{eV}$ in the photoelectron spectrum, while, on the contrary, we assign to the $5^{\text {th }}$ ionization with $n \mathrm{O}$ and $n \mathrm{~N}^{1}$ character calculated at $11.21 \mathrm{eV}$. Our calculations predict the $\pi_{\mathrm{C}=\mathrm{N}}$ at 11.76 $\mathrm{eV}$, which on the basis of the correlation line in Fig. 2 should be found at the beginning of the broad band envelope centred at $13.32 \mathrm{eV}$ in the photoelectron spectrum [4].

The electronic structure of the frontier DOs suggests that the redox properties of compounds 2 and $\mathbf{5}$ can be varied essentially by substitution at the benzene ring.

\section{Compounds 3 (medazepam) and 6 (nordazepam)}

Outermost DOs of medazepam and nordazepam are shown in Fig. 6. The corresponding ionization energies are assigned and correlated in Fig. 7 where available experimental data are also reported for comparison. As observed in the previous compounds, $\mathbf{3}$ and $\mathbf{6}$ show the same succession of cationic states with IE values of the carbonilic compound $\mathbf{6}$ higher than in $\mathbf{3}$ by 
0.2-1 eV. The first four ionizations are of $\pi$ type localized in the benzene rings. A $n \mathrm{~N}^{4}$ ionization interposes between the third and fourth $\pi$ levels. The ionization with high $\pi_{\mathrm{C}=\mathrm{N}}$ character is calculated at $10.38 \mathrm{eV}$ in $\mathbf{3}$ and at $10.97 \mathrm{eV}$ in $\mathbf{6}$. The latter value is in agreement with the experimental IE at $11.2 \mathrm{eV}$ in the PE spectrum [4], while we associate the former value to the experimental band at $10.49-10.6 \mathrm{eV}[3,4]$ in agreement with the Andreocci et al. assignment [3] but in disagreement with the Khvostenko et al. assignment [4] (Fig. 7). To compare theoretical and experimental data we look at an one to one correlation between theoretical and experimental values. The very good correlations obtained, Fig. 8, give valuable support to our assignment of the ionization processes of both benzodiazepines. The PE spectrum of medazepam was reported by Khvostenko et al. [4] and by Andreocci et al. [3]. The assignment of the ionization bands proposed by the two research groups differs noticeably with each other. The first ionization energy at $7.7 \mathrm{eV}$ in [3] and $7.59 \mathrm{eV}$ in [4] was assigned to a $n \mathrm{~N}^{1}$ lone pair ionization by Andreocci et al. and to a $\pi_{\mathrm{A}}\left(\mathrm{b}_{1}\right)$ ionization by Khvostenko et al.. Our P3 results assign the first calculated ionization at $7.46 \mathrm{eV}$ to a $\pi_{\mathrm{B}}\left(\mathrm{b}_{1}\right)$ level, in agreement with Khvostenko et al.. The band in the 8.2-10.2 eV range in the PE spectrum of $\mathbf{3}$ was associated to four ionizations by Khvostenko et al., with energy level succession $\pi_{\mathrm{C}}\left(\mathrm{b}_{1}\right)<\pi_{\mathrm{C}}\left(\mathrm{a}_{2}\right)<\pi_{\mathrm{A}}\left(\mathrm{a}_{2}\right)<n \mathrm{~N}^{4}$, on the basis of the ratio area of this band envelope and the first one-electron band. On the contrary, Andreocci et al. [3] associate this multiprocesses band to five final states, in the order: $n \mathrm{~N}_{4}<\pi_{\mathrm{B}}<\pi_{\mathrm{B}}<\pi_{\mathrm{C}}<\pi_{\mathrm{C}}$. P3 calculations associate the band to five ionizations with succession $\left.\pi_{\mathrm{C}} \mathrm{b}_{1}\right)<\pi_{\mathrm{C}}\left(\mathrm{a}_{2}\right)<n \mathrm{~N}^{4}<\pi_{\mathrm{B}}\left(\mathrm{a}_{2}\right)<\pi$, on the basis of the same previous area ratio approach. This is in agreement with the results of the deconvolution of the first two ionization bands in the PE spectrum of $\mathbf{3}$ (Fig. 9), which gives an area ratio of 5.07.

In the case of compound $\mathbf{6}$ we notice only one discrepancy with the assignment proposed by Khvostenko et al. These authors assign the third band in the spectrum at $9.7 \mathrm{eV}$ to a $n \mathrm{~N}^{4}$ ionization, while we assign it to a $\pi_{\mathrm{B}}$ ionization calculated at $9.61 \mathrm{eV}$ and put the $n \mathrm{~N}^{4}$ ionization $\left(\mathrm{IE}_{\mathrm{calc}}=9.12 \mathrm{eV}\right)$ in the experimental band centred at $9.31 \mathrm{eV}$. Our assignment of the ionization processes for nordazepam does not confirm the one reported by Andreocci et al. for diazepam ( $\mathrm{N}^{1}$-methylnordazepam) [3], which associate the first two IEs to $n \mathrm{~N}^{1}$ and $n \mathrm{~N}^{4}$ ionizations, respectively. 


\section{Vertical electron affinities}

B3LYP/6-31+G* VEA values are reported in Table 1 and the electronic structure of the lowest unoccupied molecular orbitals (LUMO) of the fully optimized neutral initial state, the extra electron site, in Fig. 10. It can be seen that the extra charge in $\mathbf{3}$ is localized in both the benzene rings, while in $\mathbf{6}$ essentially in the B ring. Therefore the VEA of nordazepam can be mainly varied by substitution in the benzene B ring, and by substitution at both rings in medazepam. Data in Table 1 indicate that IEs of the diazepine seven-membered rings are predicted to be negative; the fusion of a benzene ring and the $\mathrm{C}=\mathrm{O}$ group, however, produces a significant EA increase, so both benzodiazepine show positive VEA values. IE and EA values determine the redox properties of a molecule. The obtained values indicate that medazepam is more easily oxidized (lower IE) and less easily reduced (lower EA) than nordazepam. The IE-EA energy gap, which determines the hardness value of a molecule expressed as $\eta=($ IE-EA) $/ 2$, decreases along the series as: $\eta(\mathbf{1})>\eta(\mathbf{2})>\eta(\mathbf{3})$ and $\eta(\mathbf{4})>\eta(\mathbf{5})$ $>\eta(6)$, with medazepam less hard, i.e. less stable than nordazepam. Interestingly, computed hardness values of 3,5 and $\mathbf{6}$ follow well the trend of the available experimental singlet UV transition energies [4], which seems to indicate that in the present compounds the hardness value follows the HOMO and LUMO position and that configuration interaction effects in the excitation process are comparatively similar.

\section{Summary and conclusions}

The ab initio electron propagator theory in the $\mathrm{P} 3 / \mathrm{CEP}-31 \mathrm{G}^{*}$ approximation has been used to calculate vertical ionization energies of medazepam and nordazepam and of their molecular subunits. Vertical electron affinities were obtained by a $\triangle \mathrm{SCF}$ procedure from the total energies of the anions and neutral compounds using the B3LYP/6-31+G* method. The electronic character of the ionization processes has been established through the analysis of the Dyson orbitals and compared with available experimental and theoretical data. The comparison with previous estimates shows significant divergences in many cases. Our assignment is supported by the very good correlation we obtain between theoretical and experimental IE values. The outermost cationic states and the lowest anionic state of the investigated compounds have $\pi$ character. The electron affinity of the medazepam and the ionization potential of nordazepam can be varied essentially by substitution at both the 
benzene rings, while the EA of nordazepam and the IE of medazepam can be varied by substitution at the benzene B ring. Owing to the strong electron withdrawing power of the $\mathrm{C}=\mathrm{O}$ group, nordazepam has higher $\mathrm{EA}$ and IE than medazepam; as a result medazepam is a less hard, i.e. less stable, compound than nordazepam. Interestingly hardness values of the investigated compounds follow the trend of the experimental singlet UV transition energies.

\section{Supplementary material available}

Supplementary material contain Cartesian coordinates of compounds 1-6 (Tables S1-S6) and torsional potential energy curve relative to the rotation of the benzene $\mathrm{C}$ ring for compounds 3 and 6 (Fig. S1). 


\section{References}

1. Schutz H (1982) Benzodiazepines. Springer, Heidelberg

2. Rabalais V (1977) Principles of Ultraviolet Photoelectron Spectroscopy. Wiley, New York

3. Andreocci MV, Cauletti C, Schleinitz K-D, Hess U (1988) Spectrochim Acta A 44:10791086

4. Khvostenko OG, Tzeplin EE, Lomakin GS (2002) Chem Phys Lett 355:457-464

5. Ortiz JV (1996) J Chem Phys 104:7599-7605

6. Dolgounitcheva O, Zakrzewski VG, Ortiz JV (2009) J Phys Chem A 113:14630-14635

7. Close DM, Crespo-Hernandez CE, Gorb L, Leszczynski J (2008) J Phys Chem A 112:12702-12706

8. Zhang L, Pan Y, Qi F (2009) J Theor Comput Chem 8:1103-1115

9. Ferreira AM, Seabra G, Dolgounitcheva O, Zakrzewski VG, Ortiz JV (2001) In: Cioslowski J (ed) Quantum-Mechanical Prediction of Thermochemical Data. Kluver, Dordrecht, p 131

10. Frisch MJ, Trucks GW, Schlegel HB, Scuseria GE, Robb MA, Cheeseman JR, Montgomery JA Jr, Vreven T, Kudin KN, Burant JC, Millan JM, Iyengar SS, Tomasi J, Barone V, Mennucci B, Cossi M, Scalmani G, Rega N, Petersson GA, Nakatsuji H, Hada M, Ehara M, Toyota K, Fukuda R, Hasegawa J, Ishida M, Nakajima T, Honda Y, Kitao O, Nakai H, Klene M, Li X, Knox JE, Hratchian HP, Cross JB, Adamo C, Jaramillo J, Gomperts R, Stratmann RE, Yazyev O, Austin AJ, Cammi R, Pomelli C, Ochterski JW, Ayala PY, Morokuma K, Voth GA, Salvador P, Dannenberg JJ, Zakrzewski VG, Dapprich S, Daniels AD, Strain MC, Farkas O, Malick DK, Rabuck AD, Raghavachari K, Foresman JB, Ortiz JV, Cui Q, Babzoul AG, Clifford S, Cioslowski J, Stefanov BB, Liu G, Liashenko A, Piskorz P, Komaromi I, Martin RL, Fox DJ, Keith T, Al-Laham MA, Peng CY, Nanayakkara A, Challacombe M, Gill PMW, Johnson B, Chen W, Wong MW, Gonzalez C, Pople JA (2004) Gaussian 03, Revision E01. Gaussian Inc, Wallingford, CT

11. Becke AD (1993) J Chem Phys 98:5648-5652

12. Lee C, Yang W, Parr RG (1988) Phys Rev B 37:785-789

13. Stevens W, Basch H, Krauss J (1984) J Chem Phys 81:6026-6033

14. Tiznado JV, Ona OB, Caputo MC, Ferraro MB, Fuentealba P (2009) J Chem Theor Comput 5:2265-2273 
15. Modelli A, Mussoni L, Fabbri D (2006) J Phys Chem A 110:6482-6486

16. Vijayaraj R, Subramanian V, Chattaraj PK (2009) J Chem Theor Comput 5:2744-2753

17. Gilli G, Bertolasi V, Sacerdoti M, Borea PA (1978) Acta Cryst B 34:3793-3795

18. Camerman A, Camerman N (1972) J Am Chem Soc 94:268-272

19. Dolgounitcheva O, Zakrzewski VG, Ortiz JV (2002) J Phys Chem A 106:8411-8416 


\section{Tables}

Table 1 Vertical electron affinity VEA, vertical ionization energy VIE, hardness $\eta=(V I E-$ VEA)/2, and experimental first singlet transition energy $S_{1}$ of diazepines. Values in $\mathrm{eV}$

\begin{tabular}{lllllll} 
Compound & $\mathbf{1}$ & $\mathbf{2}$ & $\mathbf{3}$ & $\mathbf{4}$ & $\mathbf{5}$ & $\mathbf{6}$ \\
$\mathrm{VIE}$ & 7.48 & 7.35 & 8.22 & 8.81 & 8.46 & 8.49 \\
$\mathrm{VEA}$ & -0.78 & -0.38 & 0.23 & -0.14 & 0.13 & 0.60 \\
$\eta^{\mathrm{a}}$ & 4.13 & 3.86 & 3.99 & 4.48 & 4.16 & 3.94 \\
$\mathrm{~S}_{1}{ }^{\mathrm{a}}$ & & & 3.47 & & 4.14 & 3.92 \\
\hline${ }^{a}$ Ref. $[4]$ & & & & & &
\end{tabular}

${ }^{\mathrm{a}}$ Ref. [4]. 


\section{Figure captions}

Fig. 1 Molecular structures of the investigated compounds determined by B3LYP/6-31G* calculations

Fig. $2 \mathrm{IE}_{\text {calc }} v s . \mathrm{IE}_{\text {exp }}$ correlations for 1,3-dihydro-2H-1,4-benzodiazepin-2-one (4)

Fig. 3 Dyson orbitals and ionization energies of compounds 1 and 4

Fig. 4 Dyson orbitals of compounds 2 and $\mathbf{5}$

Fig. 5 Correlation diagram for compound $\mathbf{2}$ and $\mathbf{5}$ and comparison with experimental data

Fig. 6 Dyson orbitals for compounds 3 and 6

Fig. 7 Correlation diagram for compounds $\mathbf{3}$ and $\mathbf{6}$ and comparison with experimental data

Fig. $8 \quad \mathrm{IE}_{\text {calc }} v s . \mathrm{IE}_{\mathrm{exp}}$ for medazepam and nordazepam

Fig. 9 Deconvolution of the 8.2-10.2 eV experimental ionization energies envelope of medazepam (Ref. [4])

Fig. 10 Lowest unoccupied molecular orbitals of the investigated compounds 


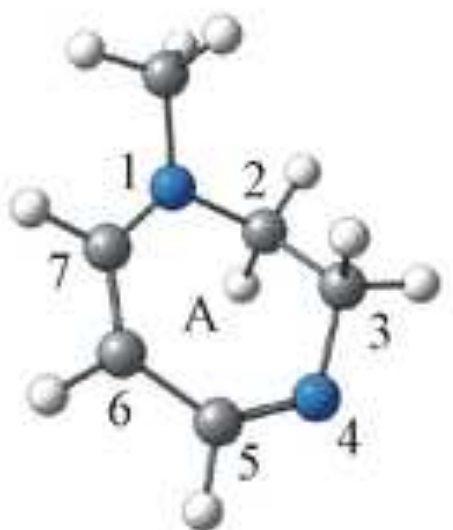

1

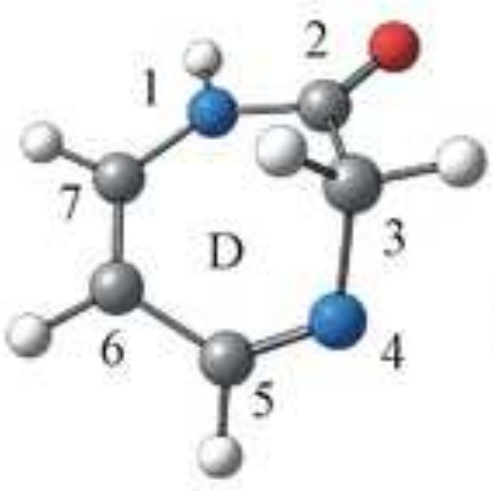

4

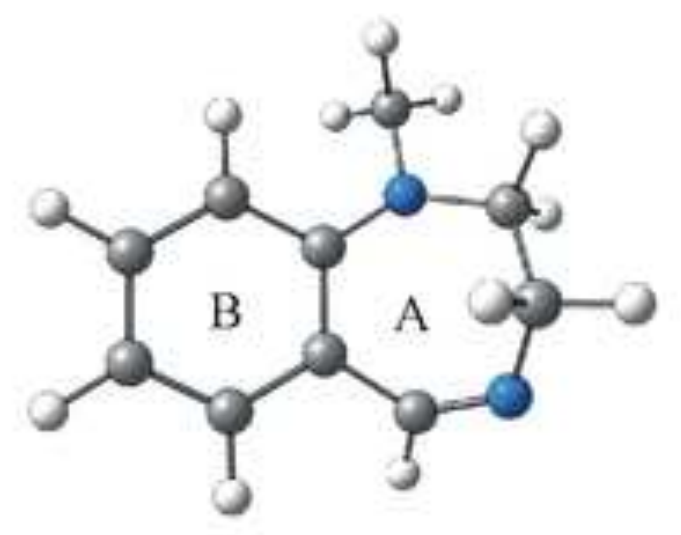

2

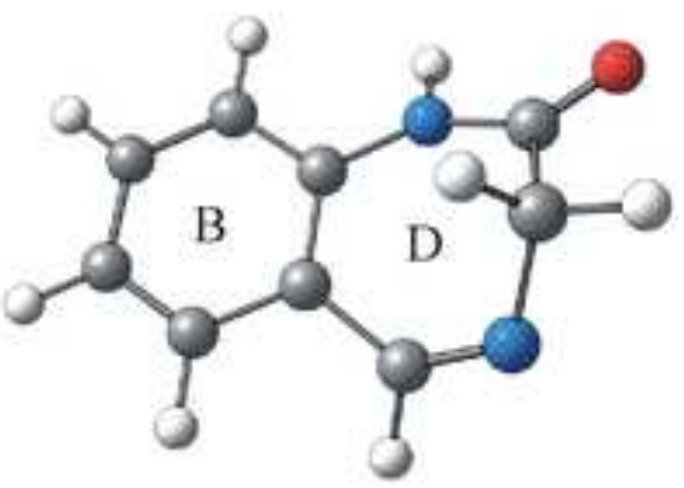

5

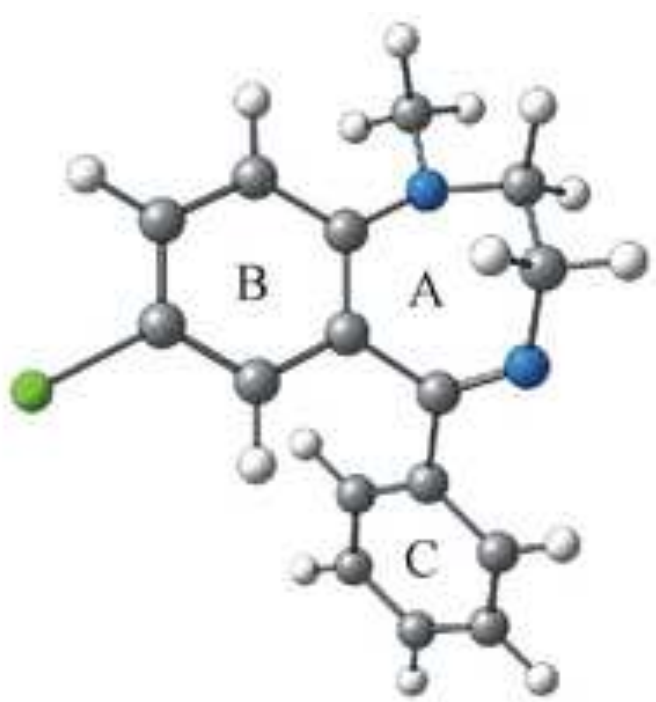

3

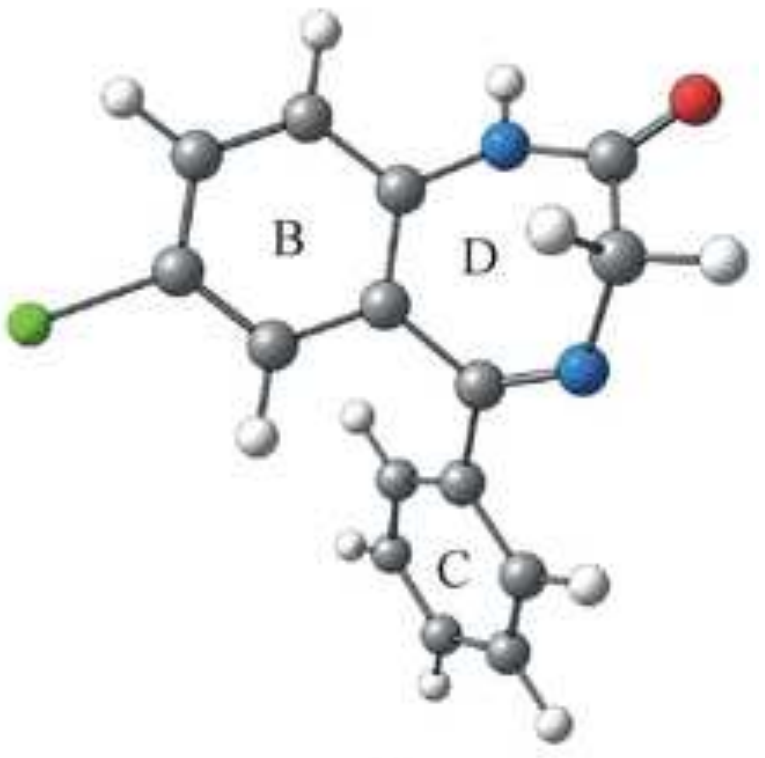

6 


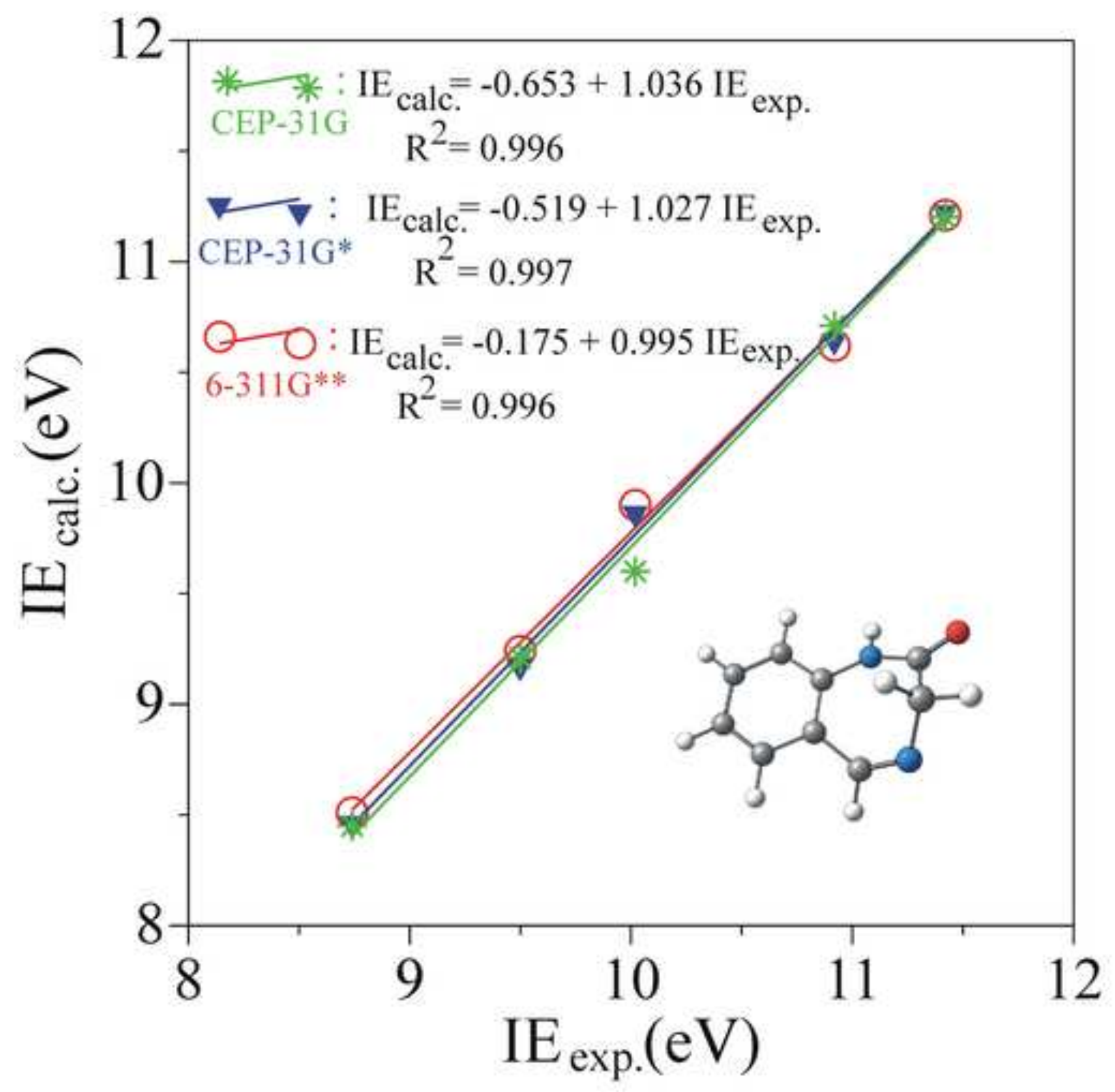




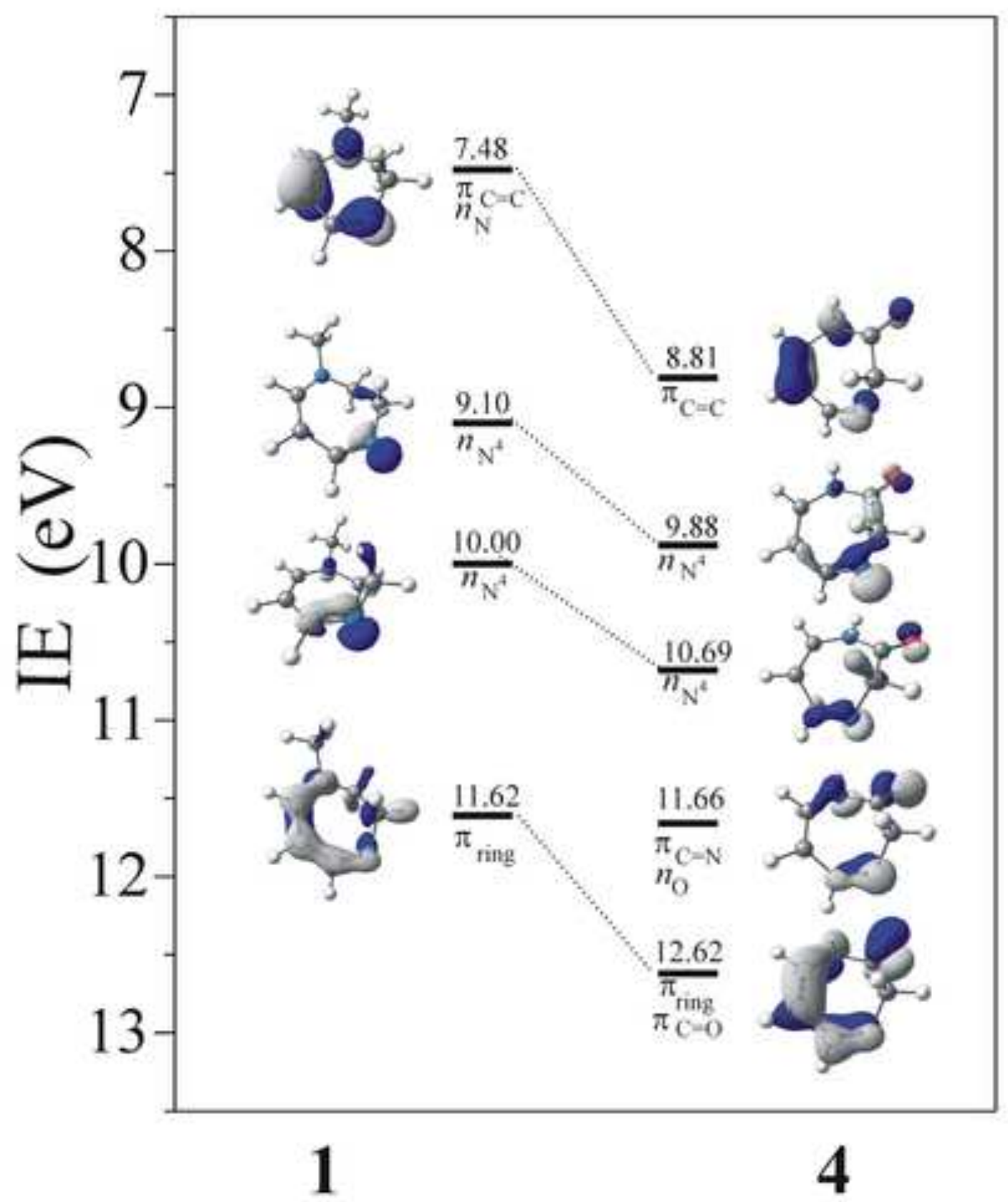


Figure 4

Click here to download high resolution image

IE
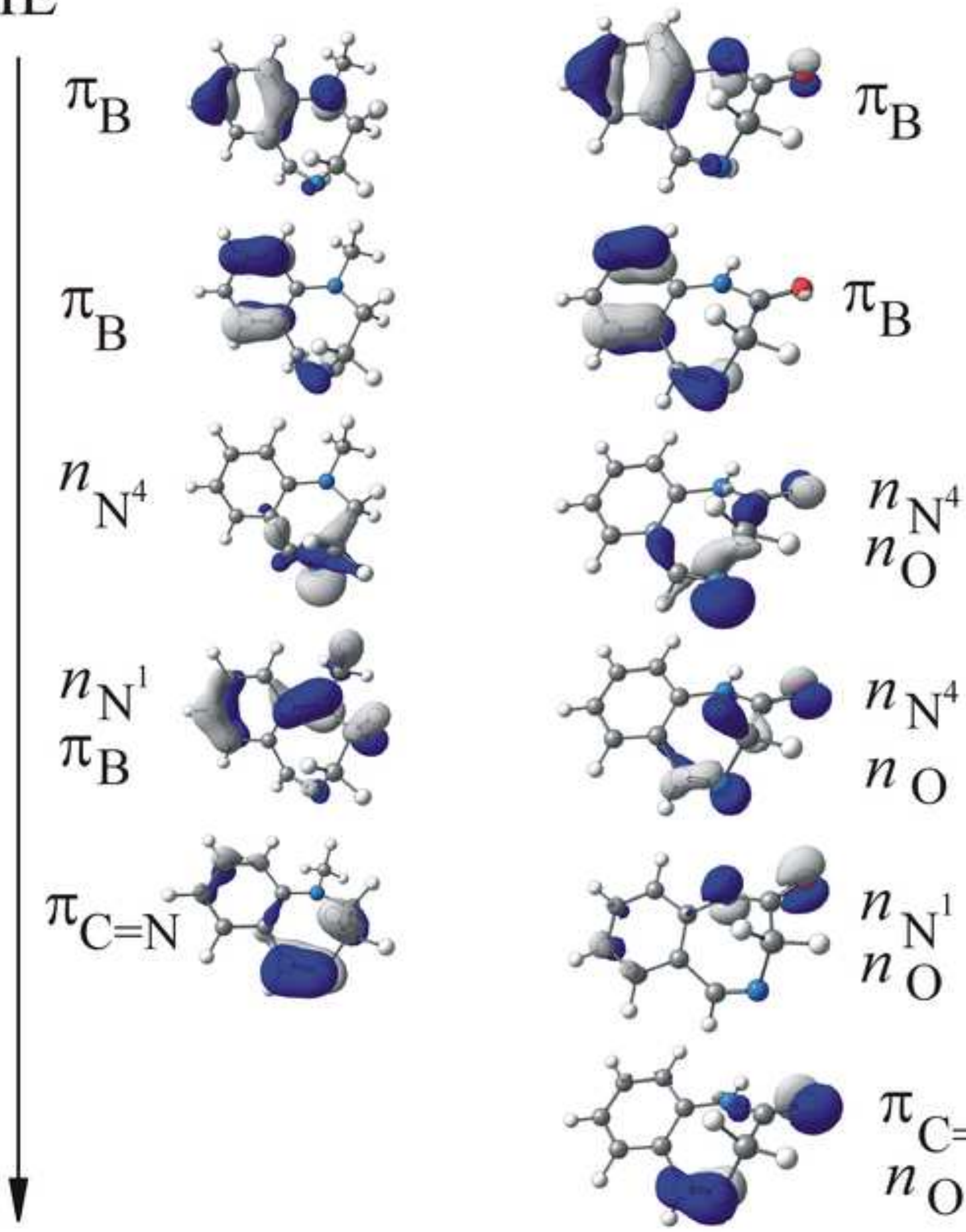

$n_{\mathrm{O}}{ }^{1}$
$n_{\mathrm{O}}$

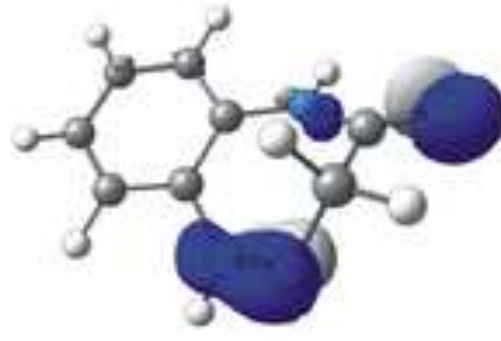

$\pi_{\mathrm{C}=\mathrm{N}}$

$n_{\mathrm{O}}$ 


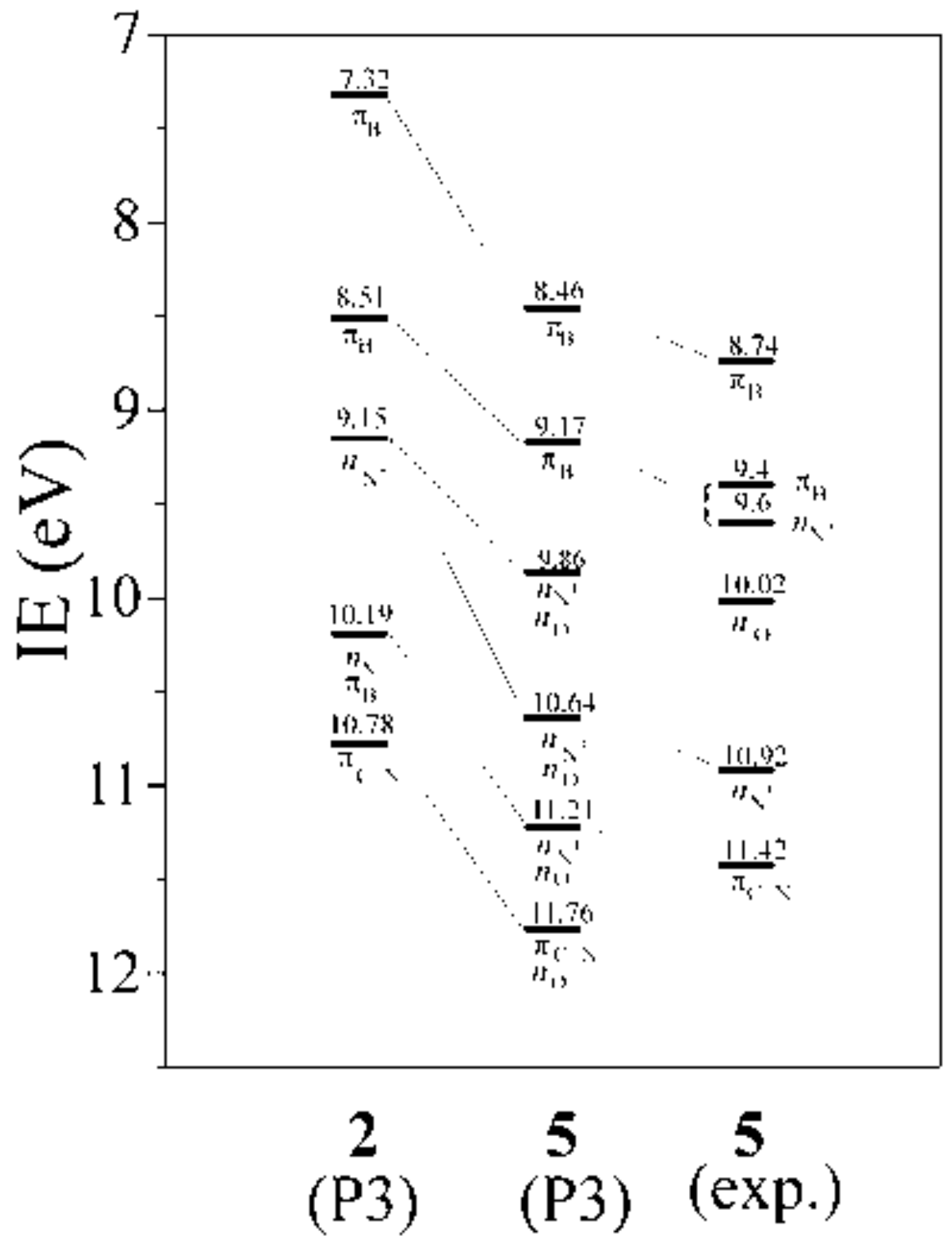




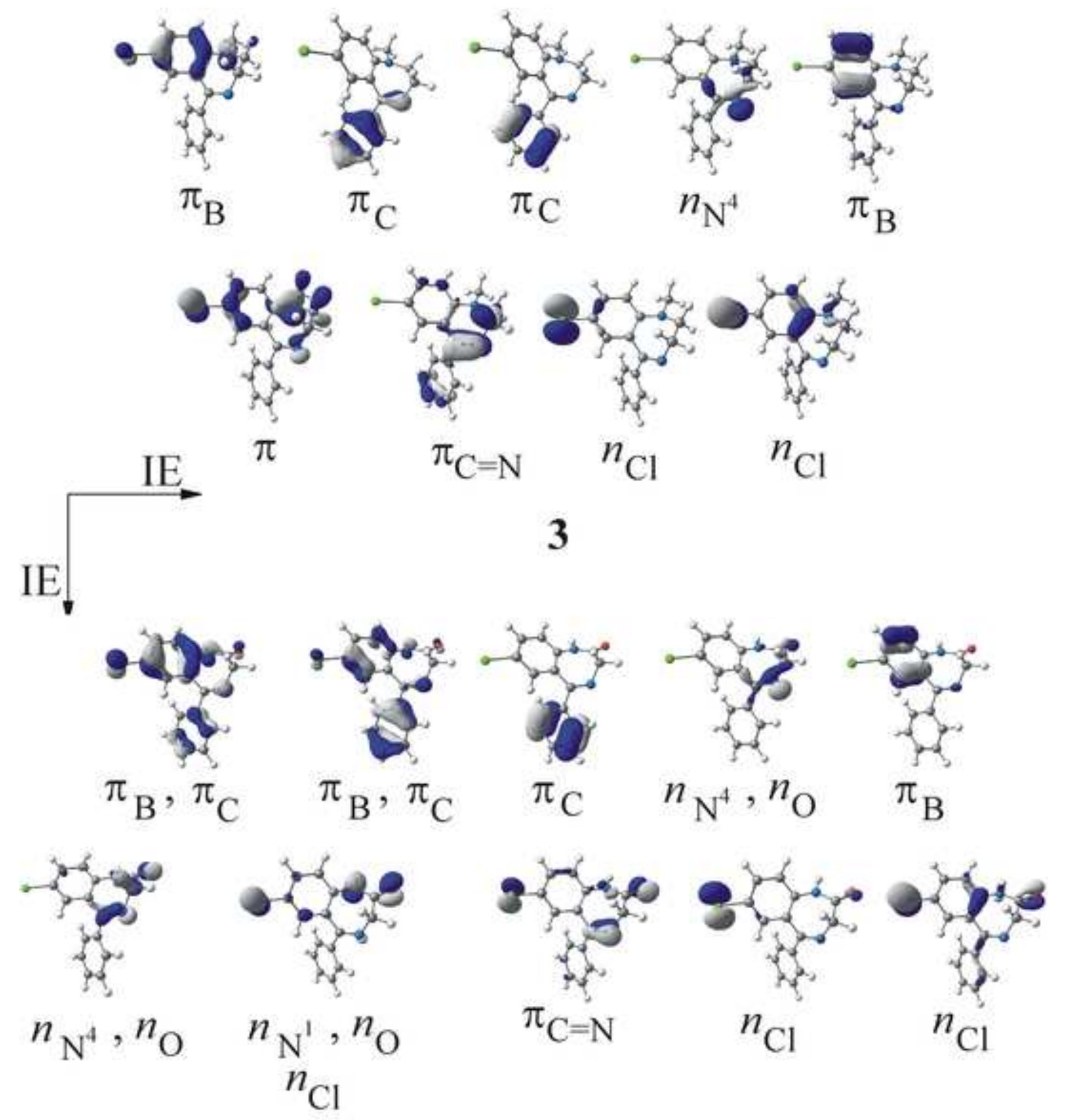

6 
7

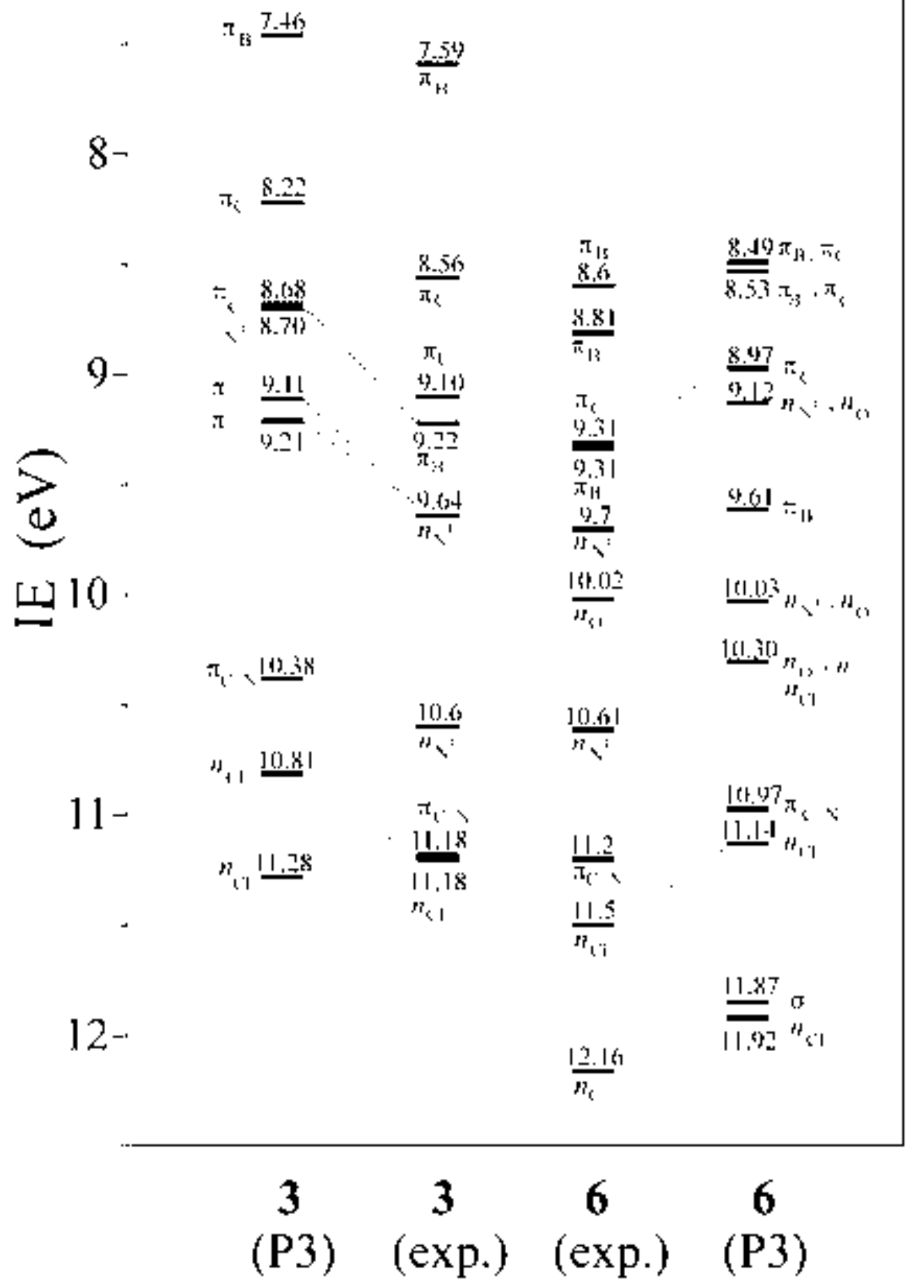




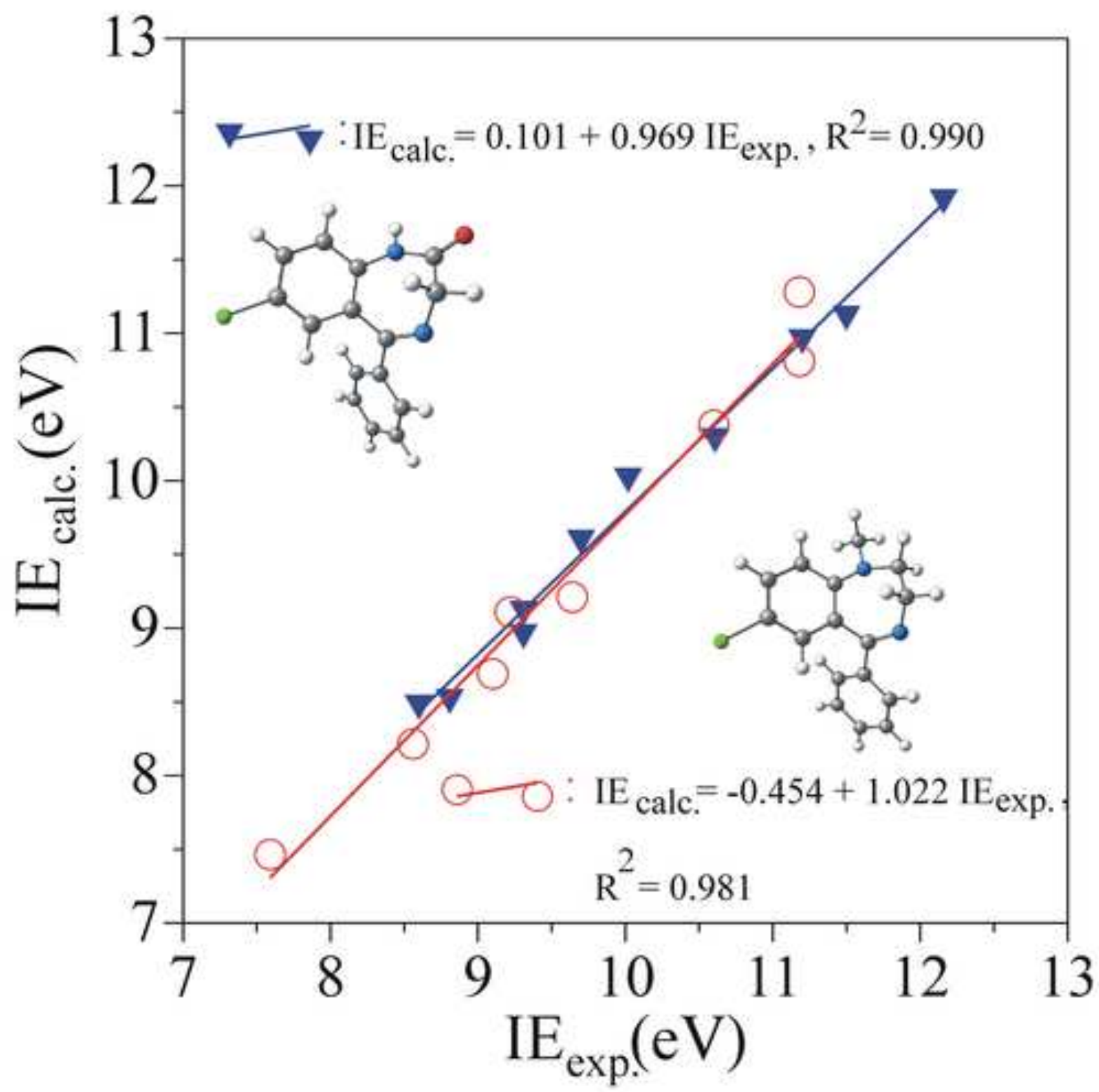




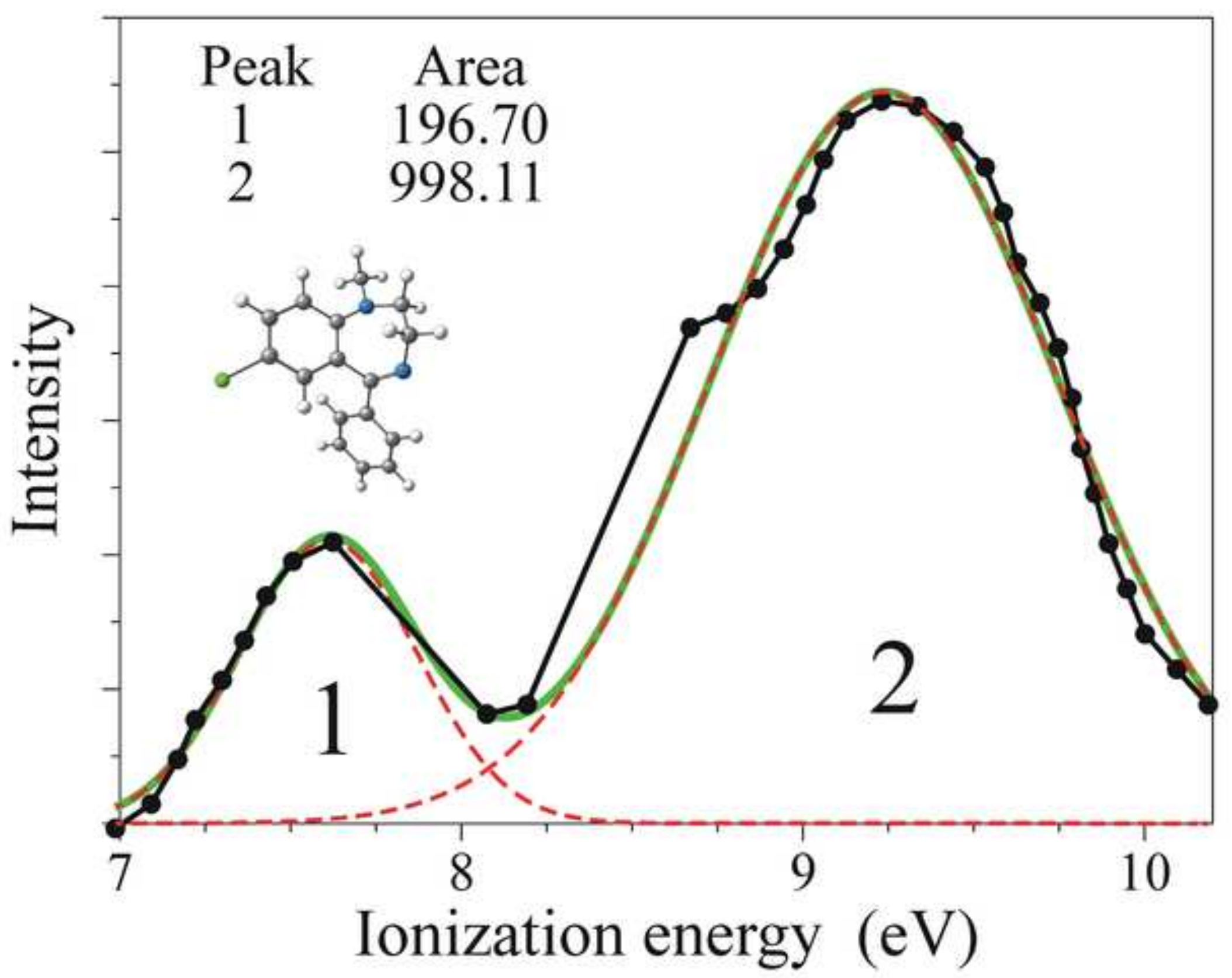


Click here to download high resolution image

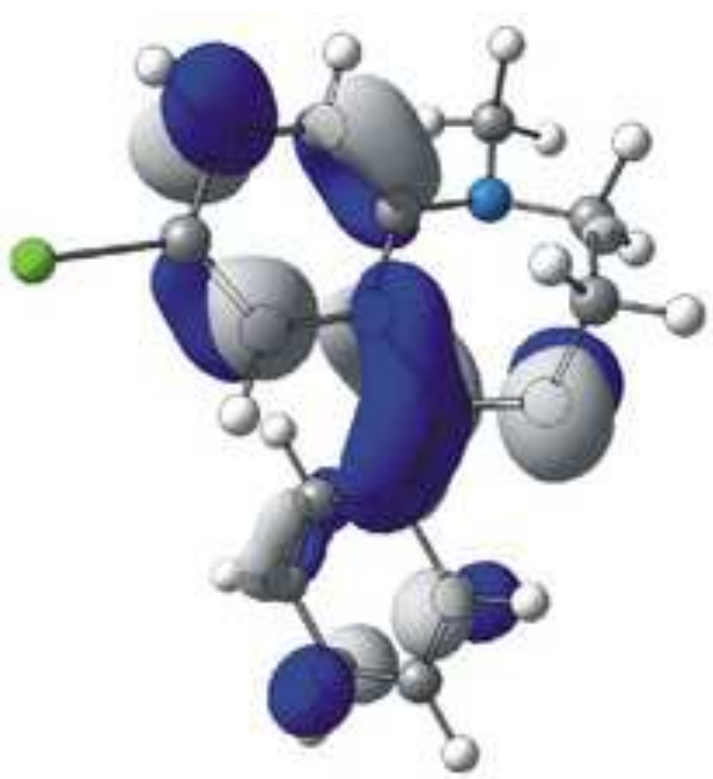

3

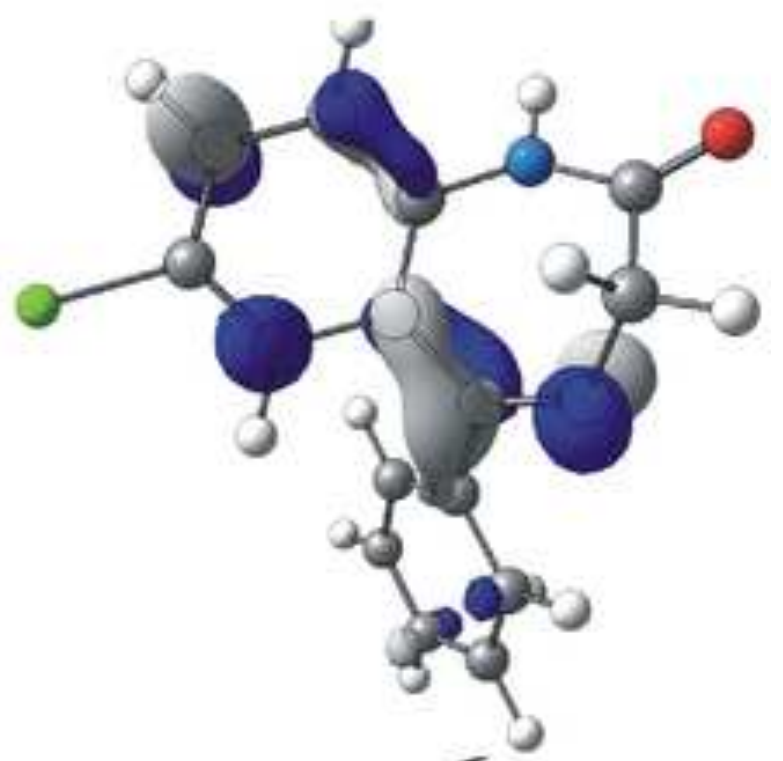

6

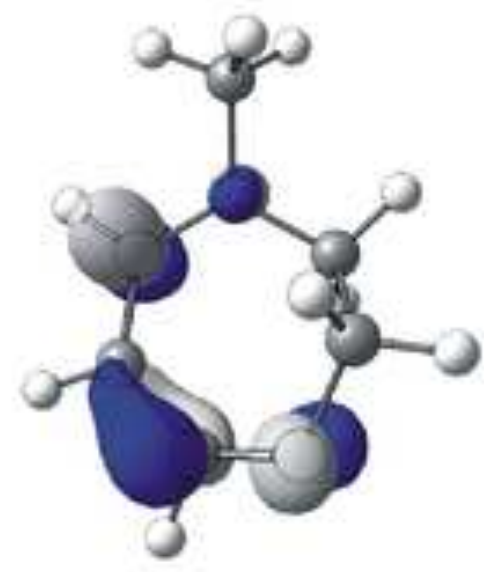

1

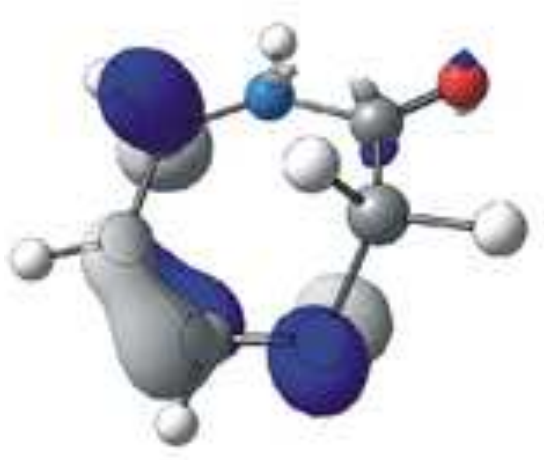

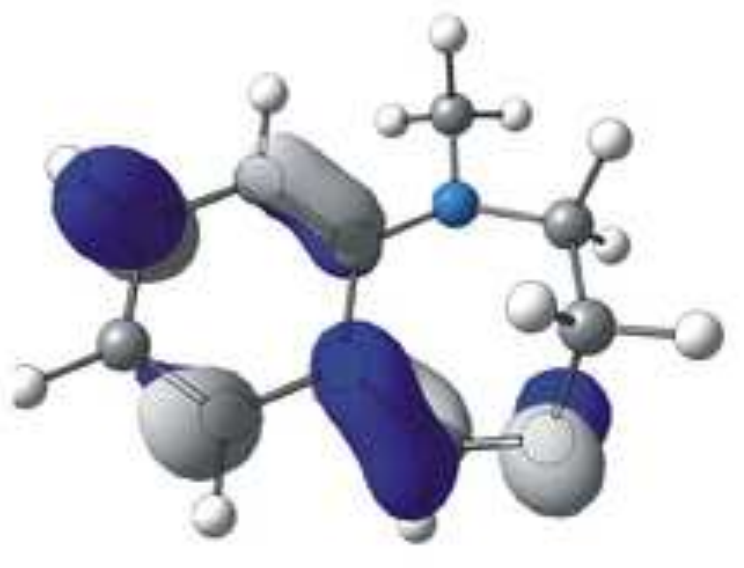

2

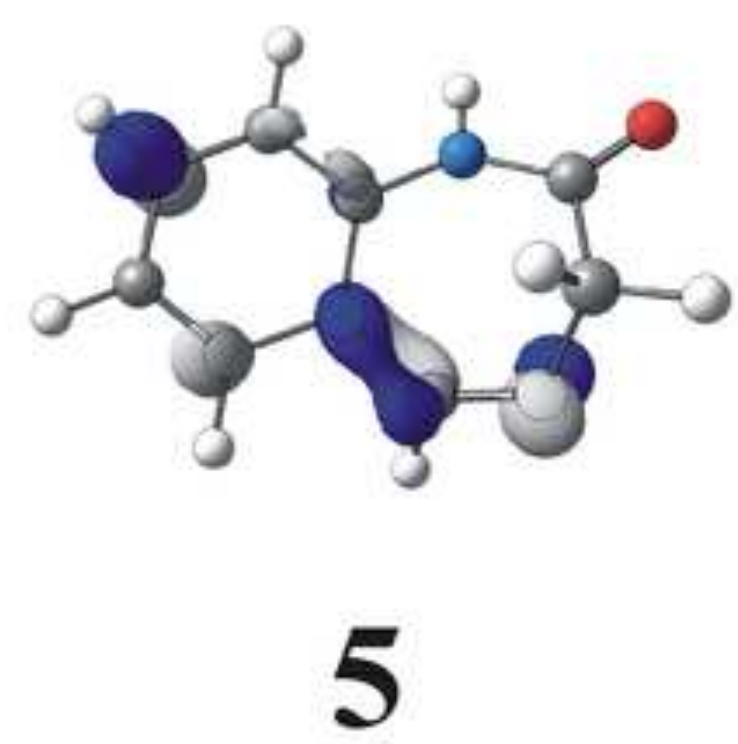

5

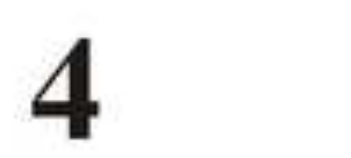




\title{
SUPPLEMENTARY MATERIAL
}

\section{Electronic properties of neuroleptics: ionization energies of benzodiazepines}

\author{
Salvatore Millefiori*, Andrea Alparone \\ Dipartimento di Scienze Chimiche,Università di Catania, \\ Viale A. Doria 8, Catania 95125, Italy
}

The data here reported are:

Fig. S1 Torsional potential energy curve relative to the benzene ring $\mathrm{C}$ rotation for compounds 3 and 6. B3LYP/6-31G* results

Table S1 Cartesian coordinates of $\mathbf{1}$

Table S2 Cartesian coordinates of 2

Table S3 Cartesian coordinates of $\mathbf{3}$

Table S4 Cartesian coordinates of 4

Table S5 Cartesian coordinates of 5

Table S6 Cartesian coordinates of 6 


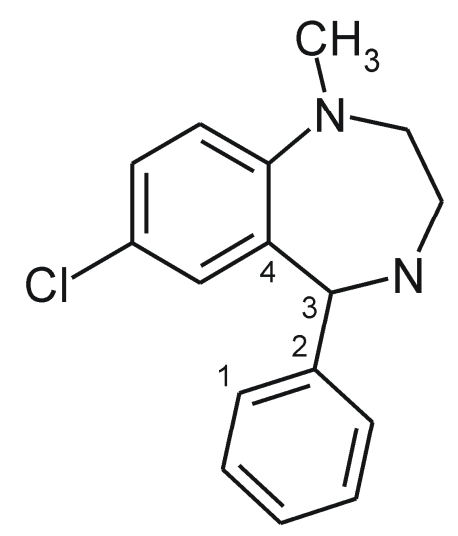

medazepam (3)

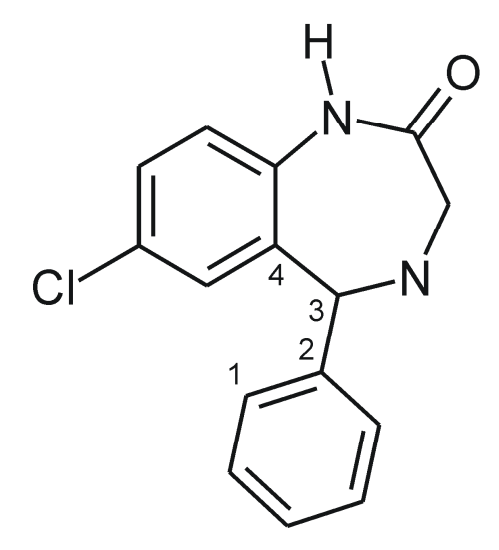

nordazepam (6)

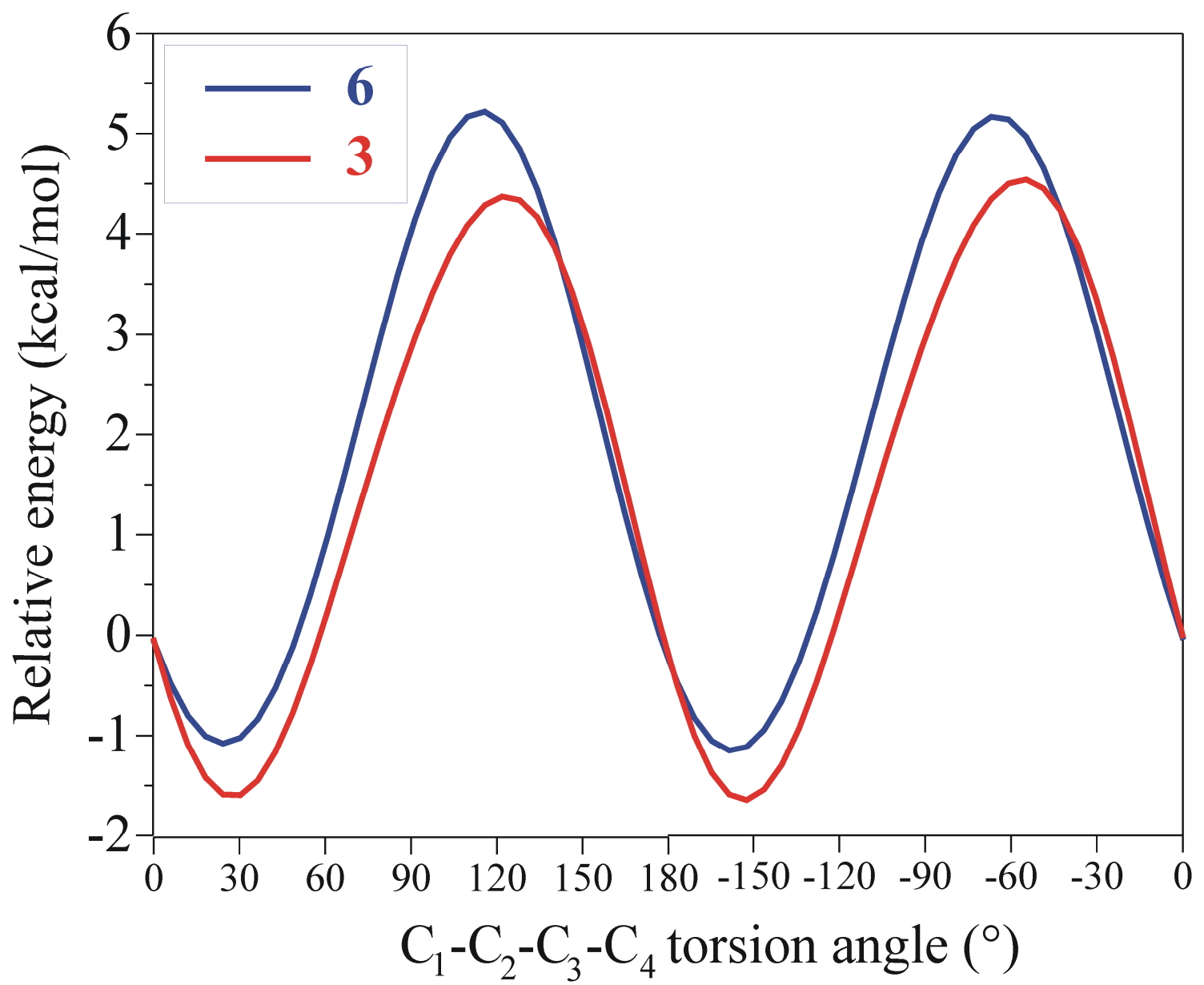

Fig. S1 
Table S1

B3LYP/6-31G* Cartesian coordinates $(\AA)$ of $\mathbf{1}$

$\begin{array}{rrrr}\mathrm{N} & 1.966137000 & -0.713838000 & -0.112221000 \\ \mathrm{C} & -0.513137000 & 1.292903000 & 0.006634000 \\ \mathrm{C} & 0.835390000 & 1.515175000 & -0.007548000 \\ \mathrm{C} & 1.934067000 & 0.566775000 & 0.035841000 \\ \mathrm{C} & 0.726295000 & -1.406771000 & -0.385755000 \\ \mathrm{C} & -0.432183000 & -1.069094000 & 0.597263000 \\ \mathrm{~N} & -1.181223000 & 0.128019000 & 0.246121000 \\ \mathrm{C} & -2.526609000 & -0.043813000 & -0.279710000 \\ \mathrm{H} & -2.526539000 & -0.527319000 & -1.269700000 \\ \mathrm{H} & -3.126028000 & -0.655021000 & 0.403292000 \\ \mathrm{H} & -3.007591000 & 0.933263000 & -0.380395000 \\ \mathrm{H} & -1.140485000 & -1.901581000 & 0.644055000 \\ \mathrm{H} & -0.003027000 & -0.940202000 & 1.597802000 \\ \mathrm{H} & 0.375593000 & -1.192504000 & -1.408096000 \\ \mathrm{H} & 0.922230000 & -2.485221000 & -0.336435000 \\ \mathrm{H} & 2.911527000 & 1.031982000 & 0.203700000 \\ \mathrm{H} & -1.174049000 & 2.145872000 & -0.139912000 \\ \mathrm{H} & 1.131029000 & 2.560408000 & -0.051956000\end{array}$


Table S2

B3LYP/6-31G* Cartesian coordinates $(\AA)$ of 2

$\begin{array}{rrrr}\mathrm{N} & 1.865077000 & -1.891510000 & -0.211799000 \\ \mathrm{C} & -0.360914000 & 0.508996000 & -0.024779000 \\ \mathrm{C} & -0.488859000 & -0.914528000 & -0.001743000 \\ \mathrm{C} & 0.589953000 & -1.923358000 & -0.123096000 \\ \mathrm{C} & 2.632588000 & -0.668291000 & -0.132731000 \\ \mathrm{C} & 1.997900000 & 0.492875000 & 0.638892000 \\ \mathrm{C} & -1.542320000 & 1.284263000 & -0.022952000 \\ \mathrm{H} & -1.473100000 & 2.365307000 & -0.025512000 \\ \mathrm{C} & -2.802351000 & 0.698663000 & 0.016098000 \\ \mathrm{H} & -3.682449000 & 1.336815000 & 0.021372000 \\ \mathrm{C} & -2.937046000 & -0.689883000 & 0.066805000 \\ \mathrm{C} & -1.785099000 & -1.464307000 & 0.056314000 \\ \mathrm{H} & -1.873036000 & -2.548231000 & 0.072960000 \\ \mathrm{~N} & 0.882256000 & 1.126245000 & -0.059363000 \\ \mathrm{C} & 0.967507000 & 2.562735000 & -0.263130000 \\ \mathrm{H} & 0.646047000 & 3.152833000 & 0.611913000 \\ \mathrm{H} & 2.004652000 & 2.825597000 & -0.487729000 \\ \mathrm{H} & 0.356593000 & 2.861224000 & -1.120593000 \\ \mathrm{H} & 1.674614000 & 0.131169000 & 1.626317000 \\ \mathrm{H} & 2.761660000 & 1.256771000 & 0.813808000 \\ \mathrm{H} & 0.173483000 & -2.936499000 & -0.170514000 \\ \mathrm{H} & -3.916907000 & -1.155980000 & 0.102259000 \\ \mathrm{H} & 2.878468000 & -0.336227000 & -1.150644000 \\ \mathrm{H} & 3.590490000 & -0.918916000 & 0.346435000\end{array}$


Table S3

B3LYP/6-31G* Cartesian coordinates ( $\mathrm{A})$ of $\mathbf{3}$

$\begin{array}{lrrc}\mathrm{N} & 0.794580000 & -1.948238000 & -1.103965000 \\ \mathrm{C} & -1.652100000 & -0.740284000 & 0.316314000 \\ \mathrm{C} & -0.513379000 & -0.073079000 & -0.220135000 \\ \mathrm{C} & 0.756008000 & -0.814913000 & -0.498420000 \\ \mathrm{C} & -0.466582000 & -2.509539000 & -1.560367000 \\ \mathrm{C} & -1.278086000 & -3.091837000 & -0.407850000 \\ \mathrm{C} & -2.797888000 & 0.028329000 & 0.595939000 \\ \mathrm{H} & -3.679560000 & -0.451566000 & 1.005656000 \\ \mathrm{C} & -2.845892000 & 1.395969000 & 0.337088000 \\ \mathrm{H} & -3.745217000 & 1.963411000 & 0.553093000 \\ \mathrm{C} & -1.736653000 & 2.024222000 & -0.222442000 \\ \mathrm{C} & -0.579892000 & 1.299529000 & -0.492295000 \\ \mathrm{H} & 0.287591000 & 1.803743000 & -0.903741000 \\ \mathrm{Cl} & -1.789743000 & 3.747547000 & -0.574598000 \\ \mathrm{~N} & -1.590407000 & -2.106400000 & 0.638867000 \\ \mathrm{C} & 2.055358000 & -0.220224000 & -0.061815000 \\ \mathrm{C} & 2.139750000 & 0.679181000 & 1.012971000 \\ \mathrm{C} & 3.239590000 & -0.603311000 & -0.715290000 \\ \mathrm{H} & 1.239500000 & 0.973444000 & 1.542757000 \\ \mathrm{H} & 3.169613000 & -1.306641000 & -1.538056000 \\ \mathrm{C} & 3.375194000 & 1.184982000 & 1.421130000 \\ \mathrm{C} & 4.469731000 & -0.092694000 & -0.311764000 \\ \mathrm{H} & 3.422979000 & 1.874623000 & 2.259634000 \\ \mathrm{H} & 5.375115000 & -0.391764000 & -0.833498000 \\ \mathrm{C} & 4.542537000 & 0.805043000 & 0.758242000 \\ \mathrm{H} & 5.503467000 & 1.204428000 & 1.071869000 \\ \mathrm{C} & -2.538326000 & -2.627696000 & 1.608411000 \\ \mathrm{H} & -3.553847000 & -2.778214000 & 1.199077000 \\ \mathrm{H} & -2.176901000 & -3.600744000 & 1.959001000 \\ \mathrm{H} & -2.604015000 & -1.959057000 & 2.471052000 \\ \mathrm{H} & -2.210909000 & -3.521305000 & -0.819428000 \\ \mathrm{H} & -0.719186000 & -3.913425000 & 0.057642000 \\ \mathrm{H} & -1.075272000 & -1.763783000 & -2.094547000 \\ \mathrm{H} & -0.253167000 & -3.321046000 & -2.264956000\end{array}$


Table S4

B3LYP/6-31G* Cartesian coordinates $(\AA)$ of 4

$\begin{array}{rrrc} & & & \\ \mathrm{O} & 2.433977000 & -0.066657000 & -0.306542000 \\ \mathrm{~N} & 0.576555000 & 1.221908000 & -0.102366000 \\ \mathrm{~N} & -0.667373000 & -1.562313000 & -0.238059000 \\ \mathrm{C} & 1.263283000 & 0.008547000 & 0.011841000 \\ \mathrm{C} & 0.447124000 & -1.135956000 & 0.604541000 \\ \mathrm{C} & -1.666015000 & -0.763792000 & -0.354209000 \\ \mathrm{C} & -1.785329000 & 0.615947000 & 0.097052000 \\ \mathrm{C} & -0.754823000 & 1.493445000 & 0.155618000 \\ \mathrm{H} & 1.185322000 & 2.000448000 & -0.327085000 \\ \mathrm{H} & 0.081751000 & -0.812948000 & 1.593249000 \\ \mathrm{H} & -2.531918000 & -1.160224000 & -0.893844000 \\ \mathrm{H} & 1.135641000 & -1.971847000 & 0.737520000 \\ \mathrm{H} & -0.948762000 & 2.539942000 & 0.376243000 \\ \mathrm{H} & -2.783559000 & 1.011570000 & 0.260178000\end{array}$


Table S5

B3LYP/6-31G* Cartesian coordinates $(\AA)$ of 5

$\begin{array}{rrrr}\mathrm{O} & -3.117235000 & -1.272728000 & -0.167126000 \\ \mathrm{~N} & -0.861965000 & -1.140062000 & -0.337160000 \\ \mathrm{~N} & -1.559151000 & 1.799539000 & -0.084751000 \\ \mathrm{C} & -2.100026000 & -0.637760000 & 0.042292000 \\ \mathrm{C} & -2.070118000 & 0.714097000 & 0.747602000 \\ \mathrm{C} & -0.324641000 & 1.786218000 & -0.415278000 \\ \mathrm{C} & 2.042381000 & 1.181076000 & -0.034873000 \\ \mathrm{C} & 3.078974000 & 0.276008000 & 0.148766000 \\ \mathrm{C} & 2.789428000 & -1.093177000 & 0.184485000 \\ \mathrm{C} & 1.479558000 & -1.535242000 & 0.049489000 \\ \mathrm{C} & 0.703902000 & 0.763619000 & -0.156883000 \\ \mathrm{C} & 0.422948000 & -0.622859000 & -0.119253000 \\ \mathrm{H} & -0.918349000 & -2.095652000 & -0.671436000 \\ \mathrm{H} & -1.464022000 & 0.611362000 & 1.662281000 \\ \mathrm{H} & 2.254072000 & 2.246350000 & -0.088997000 \\ \mathrm{H} & 3.587747000 & -1.818220000 & 0.315423000 \\ \mathrm{H} & 1.257205000 & -2.599325000 & 0.071909000 \\ \mathrm{H} & 4.101575000 & 0.625775000 & 0.251635000 \\ \mathrm{H} & 0.031161000 & 2.664735000 & -0.963514000 \\ \mathrm{H} & -3.098128000 & 0.938582000 & 1.035004000\end{array}$


Table S6

B3LYP/6-31G* Cartesian coordinates $(\AA)$ of 6

$\begin{array}{lrrr}\mathrm{N} & -0.741219000 & 2.009970000 & -0.808877000 \\ \mathrm{C} & 1.732155000 & 0.701967000 & 0.477415000 \\ \mathrm{C} & 0.606879000 & 0.073403000 & -0.106046000 \\ \mathrm{C} & -0.668591000 & 0.810945000 & -0.347929000 \\ \mathrm{C} & 0.476434000 & 2.713902000 & -1.172930000 \\ \mathrm{C} & 1.268110000 & 3.128091000 & 0.065719000 \\ \mathrm{C} & 2.879398000 & -0.058252000 & 0.762771000 \\ \mathrm{H} & 3.734933000 & 0.428898000 & 1.223300000 \\ \mathrm{C} & 2.945678000 & -1.408559000 & 0.449075000 \\ \mathrm{H} & 3.839638000 & -1.982945000 & 0.666624000 \\ \mathrm{C} & 1.850550000 & -2.015035000 & -0.171642000 \\ \mathrm{C} & 0.696058000 & -1.291459000 & -0.435978000 \\ \mathrm{H} & -0.153815000 & -1.782956000 & -0.895186000 \\ \mathrm{Cl} & 1.934171000 & -3.713408000 & -0.610032000 \\ \mathrm{~N} & 1.728923000 & 2.060832000 & 0.830940000 \\ \mathrm{C} & -1.961326000 & 0.125399000 & -0.040876000 \\ \mathrm{C} & -2.070865000 & -0.840304000 & 0.972824000 \\ \mathrm{C} & -3.116890000 & 0.492541000 & -0.751565000 \\ \mathrm{H} & -1.195425000 & -1.122330000 & 1.549282000 \\ \mathrm{H} & -3.031057000 & 1.248821000 & -1.524264000 \\ \mathrm{C} & -3.303028000 & -1.427243000 & 1.264379000 \\ \mathrm{C} & -4.343340000 & -0.100291000 & -0.465282000 \\ \mathrm{H} & -3.371823000 & -2.166260000 & 2.057973000 \\ \mathrm{H} & -5.225807000 & 0.187449000 & -1.030430000 \\ \mathrm{C} & -4.441047000 & -1.063551000 & 0.543563000 \\ \mathrm{H} & -5.398993000 & -1.525847000 & 0.766191000 \\ \mathrm{H} & 1.131565000 & 2.101575000 & -1.814973000 \\ \mathrm{H} & 0.217661000 & 3.629314000 & -1.706894000 \\ \mathrm{O} & 1.498736000 & 4.277159000 & 0.387442000 \\ \mathrm{H} & 2.367358000 & 2.350014000 & 1.563945000\end{array}$

